\title{
Students' Perspective On Using Internet Based Dental Educational Videos As An Adjunct In Dental Education
}

\author{
Hira Mateen, Ayesha Aslam, Zobash Jafer
}

ABSTRACT

Objective: The aim of this study was to observe students' perspective regarding the role of internet-based education as a supplementing tool in dental education.

Study Design and Setting: A cross-sectional survey was designed and carried out among the dental students of Margalla Institute of Health Sciences, Rawalpindi in March 2018.

Methodology: Approximately two hundred and five regular undergraduate dental students of $2^{\text {nd }}, 3^{\text {rd }}$ and final year BDS were included with an overall response rate of $100 \%$. A self-administered close-ended questionnaire was used regarding the student's perspective of using internet based educational videos during their course of dental education. Data was analyzed using SPSS version .24. Descriptive statistics was calculated.Chisquare test was used. $\mathrm{P}<0.05$ was taken as significant.

Result: Majority of the students (97.6\%) considered internet based dental educational videos (IBDEVs) was a significant supplementing tool in dental education and agreed that the knowledge gained by internet based dental educational videos was retainable and reproducible. A greater frequency of students $(88.8 \%)$ searched for videos based on clinical procedures than those for theory-based topics. No significant difference was observed between males and females as well as students of different years regarding opinion about significance of IBDEVs and their frequency of use ( $\mathrm{P}>.05)$.

Conclusion: Internet based dental educational videos (IBDEVs) were used as a beneficial supplementing tool by dental undergraduate students to enhance their understanding of a topic and improve overall learning.

Keywords: Dental Education, Surveys and Questionnaires, Visual Aid, Educational Technology

\section{INTRODUCTION:}

The need and benefits of technology in today's era cannot be overemphasized. Use of internet has seeped into our daily lives and made us dependent on it. Students today are more digitally oriented and driven than those of preinformation technology age. They tend to be attracted to and engaged in activities that involve use of technology especially internet, and expect a greater use of multimedia for teaching and learning. Literature reveals that use of internet is more frequent among contemporary dental undergraduate students than medical students.

Owing to the widespread use of portable gadgets such as smartphones and laptops, students have access to internet all the time 'on the go', making it easier to access information within no time. This generation of students are technolog-

\footnotetext{
- - - - - - - - - - - -

Lecturer, Department of Dental Materials

Margalla Institute of Health Sciences, Rawalpindi, Pakistan

I E-mail: hira.dm@margalla.edu.pk

I Ayesha Aslam

I Senior Registrar, Department of Prosthodontics

Army Medical College / Armed Forces Institute of Dentistry

National University of Medical Sciences (NUMS), Islamabad, I

I Pakistan.

Zobash Jafer

I Lecturer, Department of Dental Materials

| Margalla Institute of Health Sciences, Rawalpindi, Pakistan

I Received: 23-11-18

I Accepted: 26-02-19 $---------\ldots]$
}

ically savvy and immersed in the web, heavily engaged in gaming and internet surfing and social networking applications. Two widely used social media platforms are Facebook and Youtube. The students tend to prefer pictures and videos over lengthy demonstrations, expect immediate feedback, and demand instructions that are fun, interactive and non-linear.

Due to the pressure exerted by advances in technology, faculty shortages and student demand for flexible learning, the momentum of educational technological growth is likely to continue to increase in the future. The same applies to dental education with respect to digital or video-based learning. The term 'video-based learning' refers to the technology that is electronically taking and distributing sequences of educational image displaying scenes in motion. The videos are a rich and powerful tool for computer-assisted learning. Infect, an official you-tube channel of American Dental Association has been launched and offering free access to innumerable videos covering a wide range of topics such as oral hygiene, oral care for pediatric and geriatric patients, dental care during pregnancy etc. These videos that are now instrumental for student learning which were previously been used only for educating patients.

Advancements in technology have brought a paradigm shift in medical education with greater emphasis on a student centered approach. Clinical education and training is primarily obtained through senior faculty professors giving verbal or written instruction along with live demonstrations, lectures, 
laboratory and clinical sessions. Clinical education of specific skills continues to be the most time-consuming aspect of education in dentistry. Today, not only instructors but students need to be better equipped to cater the changing educational requirements. Use of videos as a supplementing tool in education is not a new concept. However, content that was previously restricted or available on payment is now available free of cost, easy to access and is of standard and evidenced content. For subjects that involve psychomotor skills in clinical subjects of dentistry; the educational videos can serve as a supplemented guide to improve learning and clarify concepts.Incorporating the use of instructional videos made for specific clinical skills have been advocated to assist students to achieve better academic out comes and better clinical skill performances even as also cost effective by decreasing the need of faculty.

Currently self - directed learning is being incorporated in curricula, utilizing supplementary educational videos and internet content becomes mandatory for the student. Although the impact of video and multimedia technologies in educational outcomes is afield of ongoing research, a summary of the impact of videos can be defined by three key concepts; interactivity with content, engagement and knowledge transfer and memory. Today, video plays a significant role in education in terms of its integration into traditional classes, and become the principal delivery system of information in classes particularly in online courses as well as serving as a foundation for many blended classes.

Research has formerly been focused to evaluate the effectiveness of such videos in teaching clinical skills and achieving learning objectives. However, students' appraisal of these videos as a learning aide needs to be considered. The aim of this paper was to obtain students' perspective regarding the role of education videos as a supplementing tool in dental education. The outcome of this study would assist teachers while tailoring their teaching strategies which guide their pupils towards effective self - directed learners along with the dental school administrators to understand the perspectives of dental students while formulating decisions about dental school educational strategies.

\section{METHODOLOGY:}

Ethical approval of this study was taken from the college's ethical committee. A cross-sectional survey was designed and carried out among the students of Margalla Institute of Health Sciences, Rawalpindi in March 2018. Based on previously published data, keeping confidence interval (1á) at $95 \%$, absolute precision (d) at 0.06 , and anticipated population prevalence (P) at 0.257 , a sample size of 205 was calculated using WHO sample size calculator. The regular undergraduate students of $2^{\text {nd }}, 3^{\text {rd }}$ and final year BDS students were included in the survey whereas students of physiotherapy, pharmacy, faculty members, house officers and postgraduate trainees were excluded from the study. A self-administered close-ended questionnaire was used for data collection tool. Face validation of the questionnaire was done by faculty members of different dental departments and ambiguous questions were removed. The questionnaire was also pilot - tested to ensure its validity, reliability and relevance. A total of eleven questions were asked that encompassed different perspectives of students based on how much beneficial internet based educational videos are during their course of dental education to supplement it. The purpose of study was explained to the students and individual inquiries were answered. The information was answered anonymously, no personal data except age and gender were asked. Data was analyzed using SPSS version 24. Descriptive statistics were calculated. Categorical variables were presented as frequency and percentages. Poststratification Chisquare test was used to control effect modifiers such as gender and year of education. $\mathrm{P}<0.05$ was taken as significant.

\section{RESULTS:}

The questionnaire was filled and returned by two hundred and five dental undergraduate students with an overall response rate of $100 \%$. There were seventy-nine students $(38.5 \%)$ from $2^{\text {nd }}$ year, sixty students $(29.3 \%)$ from 3 rd year and sixty-six students (32.2\%) from final year BDS.Out of two hundred and five respondents, one hundred and sixty nine $(82.4 \%)$ were females and thirty six $(17.6 \%)$ were males. Majority of the students $(\mathrm{n}=200)$ considered internet based dental educational videos (IBDEVs) a significant supplementing tool in dental education and that the knowledge gained by IBDEVs was retainable and reproducible. Table 1 highlights the general opinion of students regarding IBDEVs. A greater frequency of students $(\mathrm{n}=182)$ searched for videos based on clinical procedures than those for theorybased topics $(11.2 \%)$. Most of students $(n=115)$ found the content of IBDEV to be moderately relevant while $60.2 \%$ $(n=123)$ found the videos to be moderately clarifying when they specifically search for a topic (see figure 1,2). Regarding the frequency of access of IBDEVs, 39.3\% $(n=81)$ replied that they required assistance of such videos on a weekly basis (see figure 3 ) while $80 \%(n=164)$ preferred searching for IBDEVs at their home. No significant difference $(\mathrm{P}>0.05)$ was observed between males and females as well as students of different years regarding opinion about significance of IBDEVs (table 2) and their frequency of use (table 3).

\section{DISCUSSION:}

One of the ways to improve the effectiveness of dental education is by introducing videos in the lectures. It has been suggested that video-based teaching is appreciated and widely acknowledged by dental undergraduate students as a good way of attaining knowledge. The present study, however, aimed to know the student's perspective with regards to the use of internet - based dental educational videos as a supplementing tool in their dental education. 


\begin{tabular}{|l|c|c|c|}
\hline \multicolumn{1}{|c|}{ Question } & \multirow{2}{*}{ N } & \multicolumn{2}{c|}{ Response (\%) } \\
\cline { 3 - 4 } & & Yes & No \\
\hline $\begin{array}{l}\text { Are internet-based dental educational videos a } \\
\text { significant tool in dental educational? }\end{array}$ & $97.6 \%$ & $2.4 \%$ \\
$\begin{array}{l}\text { Do you think internet-based dental educational } \\
\text { videos help retain the knowledge for longer } \\
\text { period? }\end{array}$ & $96.1 \%$ & $3.9 \%$ \\
$\begin{array}{l}\text { Is the knowledge learned by internet based } \\
\text { educational videos reproducible? }\end{array}$ & 205 & $95.1 \%$ & $4.9 \%$ \\
$\begin{array}{l}\text { Have you personally looked for internet based } \\
\text { educational videos on any other topic NOT } \\
\text { COVERED in class? }\end{array}$ & $77.2 \%$ & $22.8 \%$ \\
$\begin{array}{l}\text { Are you satisfied with the quality of the video } \\
\text { content available? }\end{array}$ & $83.5 \%$ & $16.5 \%$ \\
\hline
\end{tabular}

Table 1: Opinion of dental undergraduate students regarding internet based dental educational videos (IBDEV)

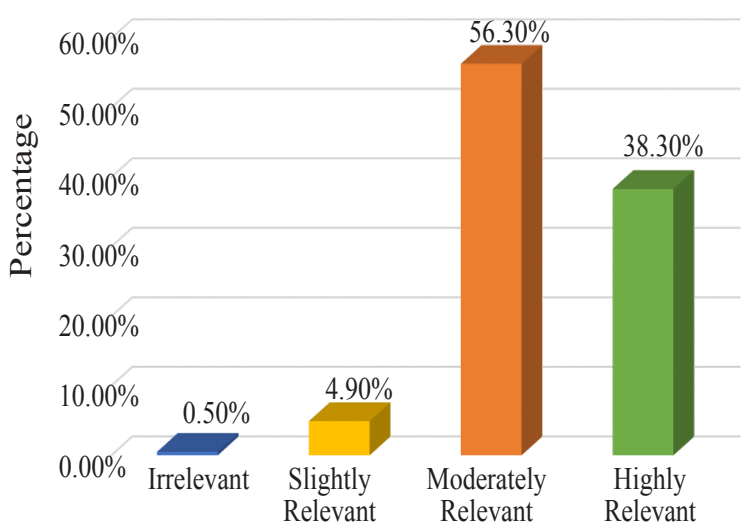

Figure 1: Relevance to clinical practice of content learned from Internet-based dental educational videos

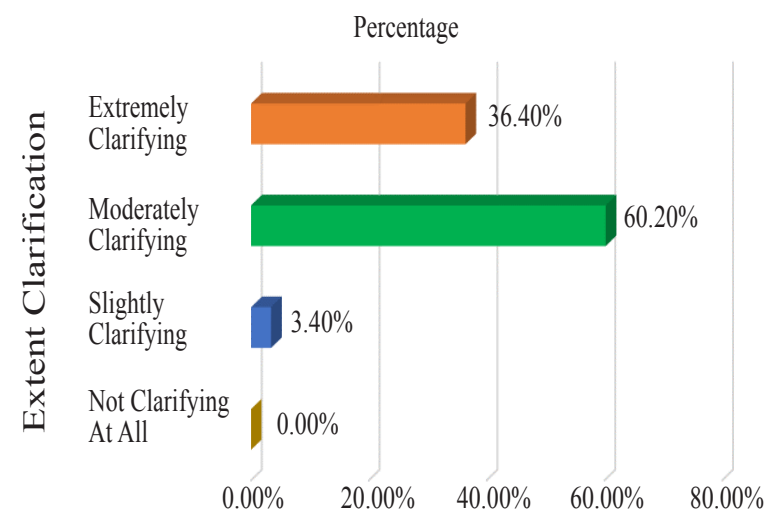

Figure 2: Extent to which IBDEVs clarify students' concepts

In the present study, majority $(n=200,97.6 \%)$ students found IBDEVs a useful supplementing tool in dental education. These findings corroborated with Al-Jandan et alin which $91.4 \%$ of students found videos a beneficial instrument in their education. Similar results were reported by Kalwitzki et alin which students favored video-based learning over lectures. A systematic review on effectiveness of various

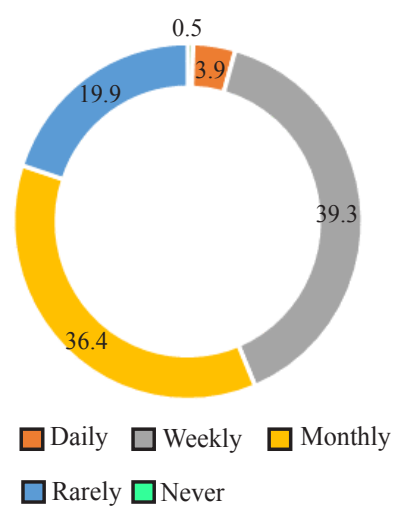

Figure 3: Frequency of access of IBDEVs as a supplementing tool

\begin{tabular}{|l|c|c|c|c|}
\hline \multirow{2}{*}{ Variable } & \multirow{2}{*}{ Response } & \multicolumn{2}{|c|}{ Gender } & \multirow{2}{*}{ P value } \\
\cline { 2 - 4 } & & Male & Female & \\
\hline \multirow{2}{*}{$\begin{array}{l}\text { IBDEV s are a significant } \\
\text { tool in dental educational }\end{array}$} & Yes & 34 & 167 & \multirow{3}{*}{0.179} \\
\cline { 2 - 4 } & No & 2 & 3 & \\
\cline { 2 - 4 } & Never & 2 & 2 & \\
\cline { 2 - 4 } $\begin{array}{l}\text { Frequency of use of } \\
\text { IBDEV }\end{array}$ & Rarely/Once in a while & 4 & 35 & \\
\cline { 2 - 4 } & Daily & 1 & 7 & \multirow{2}{*}{0.825} \\
\cline { 2 - 4 } & Weekly & 15 & 66 & \\
\cline { 2 - 4 } & Monthly & 14 & 61 & \\
\hline
\end{tabular}

Table 2: Cross-tabulation of variables with respect to gender

\begin{tabular}{|l|c|c|c|c|c|}
\hline \multirow{2}{*}{ Variable } & \multirow{2}{*}{ Response } & \multicolumn{3}{|c|}{ Year of Education } & \multirow{2}{*}{ P value } \\
\cline { 2 - 5 } & & Year 2 & Year 3 & Year 4 & \\
\hline $\begin{array}{l}\text { IBDEVs are a significant } \\
\text { tool in dental educational }\end{array}$ & Yes & 75 & 61 & 65 & \multirow{3}{*}{0.586} \\
\hline \multirow{4}{*}{$\begin{array}{l}\text { Frequency of use of } \\
\text { IBDEV }\end{array}$} & No & 3 & 2 & 2 & \\
\cline { 2 - 5 } & Never & 2 & 2 & 2 & \\
\cline { 2 - 5 } & Rarely/Once in a while & 10 & 15 & 13 & \\
\cline { 2 - 5 } & Daily & 5 & 2 & 2 & \multirow{2}{*}{0.358} \\
\cline { 2 - 5 } & Weekly & 36 & 19 & 23 & \\
\cline { 2 - 5 } & Monthly & 25 & 23 & 24 & \\
\hline
\end{tabular}

Table 3: Cross-tabulation with respect to year of education

teaching methods by Gopinath and Nallaswamy ${ }^{11}$ also observed video-based teaching as a useful adjunct to other teaching and learning strategies.

In response to questions about retention of gained knowledge, $96.1 \%$ subjects in the present study agreed that IBDEVs helped retain the knowledge for a longer period of time. Contradictory results were reported by Al-Jandan et al that majority of $(68.5 \%)$ students agreed that knowledge gained from videos is retained for a longer period but both males and females appeared rather unclear about the question. This may be attributed to varying retention capabilities of males and femalesas well as a difference in learning approaches that work for different students such as VARK. It has been suggested that males prefer multiple modes of instructions 
while females prefer a single mode, with a greater predilection for kinesthetic learning.

Approximately $60 \%$ subjects in the present study reported that IBDEVs 'moderately clarified' their concepts while $36.4 \%$ students found them 'extremely clarifying'. These findings are endorsed by those of Chi et alwho compared student learning outcomes associated with video-based learning in comparison to paper - cases. They reported that video - based learning significantly enhanced learning in cognitive and affective domains, improving the overall learning outcomes. Comparable results were also found by Naseri et althat video-assisted clinical instruction in dentistry (VACID) is an effective method to improve student learning and it minimizes the number of students who approach the teacher with questions. A similar study was carried out in Sweden by Rystedt et alby evaluating students' perception of video-based clinical demonstration where students expressed that video - based teaching helped in integrating theoretical knowledge with clinical understanding.

In dental education, a noteworthy problem is how to bridge the gap between theory and practice. Students can find it difficult and intimidating to appreciate the clinical relevance of preclinical courses and to visualize clinical scenarios. Although clinical demonstrations can be a useful tool in this regard, but limited access to oral cavity makes it difficult for all students to see adequately what is being demonstrated. This difficulty can be overcome by the use of internet-based dental educational videos as demonstrated by the present study. Such videos can serve as a supplementing tool to augment understanding. Further queries can be addressed individually during hands-on practice. The present study suffers from the weaknesses inherent in a questionnaire based survey. The responses were subject to reporting bias of study participants. Moreover, the sample size can be increased to include a more diverse sample and to generalize the results to the entire population.

With the changing paradigms of health professional education, incorporating latest teaching and learning strategies has become even more important. Internet based educational videos can play a major role in student learning. However, since the content of IBDEVs cannot be regulated or supervised, such videos should only be used as a supplementing tool and not as the primary source of learning. Any ambiguities must be discussed with the instructor and concepts verified. Moreover, quality and content of IBDEVs can be improved and regulated if prominent dental associations, organizations or teaching universities in the country upload videos tailored to the needs of preclinical and clinical students.

\section{CONCLUSION:}

Based on the findings of this study, it was concluded that dental undergraduate students considered internet based dental educational videos (IBDEVs) a significant supplementing tool in dental education and that the knowledge gained by IBDEVs was retainable and reproducible. Students preferred to search for videos based on clinical procedures and found the videos to be moderately clarifying when they specifically searched for a topic. Students accessed IBDEVs on a weekly basis, found them moderately relevant and were satisfied with the content of available videos. No significant difference was observed between males and females as well as students of different years regarding opinion about significance of IBDEVs and their frequency of use $(\mathrm{P}>.05)$. ACKNOWLEDGEMENT:

The authors would like to extend gratitude to Dr. BenishMehmood for her guidance and Class Representatives Quratul Ain Syed, Talha Arshad, AnumKhizar, Arif Ali and Osama Iqbal for assisting in questionnaire distribution.

\section{REFERENCES}

1. Jackman WM, Roberts P. Students' Perspectives on YouTube Video Usage as an E-Resource in the University Classroom. J Edu Technol Sys 2014;42(3):273-96.

2. Al-Jandan BA, Farooq I, Khan SQ. Students' perspectives on the relevance of internet-based educational videos in dental education. J Taibah Uni Med Sci 2015;10(3):288-92.

3. Romanelli F, Bird E, Ryan M. Learning Styles: A Review of Theory, Application, and Best Practices. Am J Pharm Educ 2009;73(1):09.

4. Gedam SR, Shivji IA, Goyal A, Modi L, Ghosh S. Comparison of internet addiction, pattern and psychopathology between medical and dental students. Asian J Psychiatr 2016;22:10510.

5. Jali PK, Singh S, Babaji P, Chaurasia VR, Somasundaram P, Lau H. Knowledge and attitude about computer and internet usage among dental students in Western Rajasthan, India. J Int Soc Prev Community Dent 2014;4(1):29-34.

6. Bobrow BJ, T. F. Vadeboncoeur, D. W. Spaite, J. Potts, K. Denninghoff, V. Chikani, et al. The Effectiveness of Ultrabrief and Brief Educational Videos for Training Lay Responders in HandsOnly Cardiopulmonary Resuscitation: Implications for the Future of Citizen Cardiopulmonary Resuscitation Training. Circ Cardiovasc Qual Outcomes 2011;4(2):220-6.

7. Bauk SI. Assessing Students' Perception of E-Learning in Blended Environment: An Experimental Study. Procedia Social and Behavioral Sciences 2015;191:323-9.

8. Genç E, Büyük SK, ${ }^{a} i^{\circ} \mathrm{ek} H$. An evaluation of attitudes about educational strategies, school duration, specialty and technology in a group of Turkish dental students. Gulhane Med J 2018;60(3):83-7.

9. El-Sayed R, El-Sayed S. Video-based lectures: An emerging paradigm for teaching human anatomy and physiology to student nurses. Alexandria J Med 2013;49(3):215-22.

10. Fat MJ, Doja A, Barrowman N, Sell E. YouTube videos as a teaching tool and patient resource for infantile spasms. J Child Neurol 2011;26(7):804-9.

11. Ramlogan S, Raman V, Sweet J. A comparison of two forms of teaching instruction: video vs. live lecture for education in clinical periodontology. Eur J Dent Educ 2014;18(1):318.

12. Smith W, Rafeek R, Marchan S, Paryag A. The use of videoclips as a teaching aide. Eur J Dent Educ 2012;16(2):91-6. 
13. Klenke AL. How Dental Hygiene Undergraduate Learning is Influenced by Educational Videos. Albuquerque, New Mexico: University of New Mexico; 2017.

14. M Beheshti, Taspolat A, Kaya SO, Sapanca FH. Characteristics of instructional videos. World J Educ Technol Curr Issues 2018;10(1):61-9.

15. Nikzad S, Azari A, Mahgoli H, Akhoundi N. Effect of a procedural video $\mathrm{CD}$ and study guide on the practical fixed prosthodontic performance of Iranian dental students. J Dent Educ 2012;76(3):354-9.

16. Kalwitzki M, Meller C, Beyer C. Does teaching method affect students' perceptions regarding communication patterns in pediatric dentistry? A comparison of lecture and video methods. J Dent Educ 2011;75(8):1084-91.

17. Fleming N, Baume D. Learning Styles Again: VARKing up the right tree! Educ Dev 2006;7(4):4-7.

18. Wehrwein EA, Lujan HL, DiCarlo SE. Gender differences in learning style preferences among undergraduate physiology students. Adv Physiol Educ 2007;31(2):153-7.
19. Chi DL, Pickrell JE, Riedy CA. Student learning outcomes associated with video vs. paper cases in a public health dentistry course. J Dent Educ 2014;78(1):24-30.

20. Naseri M, Shantiaee Y, Rasekhi J, Zadsirjan S, Mojtahed Bidabadi M, Khayat A. Efficacy of Video-Assisted Instruction on Knowledge and Performance of Dental Students in Access Cavity Preparation. Iran Endod J 2016;11(4):329-31.

21. Rystedt H, Reit C, Johansson E, Lindwall O. Seeing through the dentist's eyes: Video-based clinical demonstrations in preclinical dental training. J Dent Educ 2013;77(12):162938.

22. Robinson PB, Lee JW. The use of real time video magnification for the pre-clinical teaching of crown preparations. Br Dent J 2001;190(9):506-10.

23. Fakhry A, Dehkordi-Vakil FH. Video-Assisted Clinical Instruction in Dentistry (VACID) enhances real-time visualisation of clinical procedures. Eur J Dent Educ 2007;11(4):238-44.

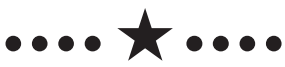

